RESEARCH PAPER RP1712

Part of Journal of Research of the National Bureau of Standards, Volume 36.

May 1946

\title{
AN ANALYSIS OF THE EFFECTS OF FUEL DISTRIBUTION ON ENGINE PERFORMANCE
}

\author{
By Donald B. Brooks
}

\section{ABSTRACT}

From an empirical equation, based on single-cylinder-engine test data and relating engine power to fuel consumption, engine-performance curves are derived analytically for typical examples of poor mixture distribution. Investigation of the resulting information shows that the minimum specific fuel consumption is a satisfactory criterion of distribution quality. A method is developed for ascertaining the attainable improvement over a given distribution.

\section{CONTENTS}

I. Objective of analysis $\quad$ Page

II. Derivation of formulas .

III. Study of different types of maldistribution

IV. Study of different degrees of maldistribution

V. Estimation of improvement attainable $\ldots \ldots \ldots \ldots$

VI. Factors not considered in analysis_._.

VII. Conclusions _ _

VIII. References

\section{OBJECTIVE OF ANALYSIS}

The effects of imperfect fuel distribution on engine performance were well known to automotive engineers a generation ago, when the increasing demand for gasoline was overtaxing the simpler refining processes then available and making it necessary to include components of relatively low volatility in motor fuel. With the advent of cracking processes, gasoline has since become a more satisfactory fuel, and manifolding an engine is no longer as much of a problem as it was. Recent work $[1,2]^{1}$ at this Bureau on substitute motor fuels, carried on at the request of and sponsored by the Foreign Economic Administration, showed that certain substitute fuels were distributed very poorly in manifolds designed for use with gasoline. With 190-proof alcohol, for example, distribution was so bad that it would seem economical to redesign the manifold for use with alcohol, if any considerable number of engines of one type were to be operated on this fuel regularly.

As such a redesign would probably involve some compromise, because of the variable composition of substitute fuels, it seemed desirable to reexamine the effect of fuel distribution on performance. Sparrow, in "The Arithmetic of Distribution" [3], presented a graphical

\footnotetext{
1 Figures in brackets refer to literature references at the end of this paper.
} 
analysis of specific manifold deficiencies on power and specific fuel consumption. In the present work, an analytical method has been used, as it is more flexible and better adapted for determining certain other relations, such as the fuel-flow rates at which minimum specific fuel consumption and maximum power occur.

\section{DERIVATION OF FORMULAS}

The computations of this analysis are based on data obtained in single-cylinder-engine tests of various fuels [1], involving some 800 measurements of engine power. These data are shown in figure 1. A smooth curve was faired through these data, plotted as percentage of maximum power against percentage of fuel consumption at peak power. Tangents to this curve were obtained graphically, and were plotted, figure 2. A formula was then sought to fit the data shown in figure 2. This method of obtaining a formula fitting the derivative, then integrating to get the desired function, has often been found more successful than the direct approach.

After several attempts, the data were fitted, as shown by the solid curve in figure 2 , by the formula

where

$$
\frac{d y}{d x}=\frac{132300}{x^{2}}-\frac{3186.9}{x}+25.651-0.07012 x
$$

$y=$ power, percentage of maximum

$x=$ fuel consumption, percentage of that at maximum power.

Upon integration and substitution of the peak coordinates to evaluate the constant of integration, this becomes

$$
y=-\frac{132300}{x}-7338.108 \log x+13884.716+25.651 x-0.03506 x^{2} \text {. }
$$

This equation, which is plotted in figure 1 , gives the relation of power to fuel consumption for the single-cylinder engine, and by extension, for a similar multicylinder engine having perfect distribution at all mixture ratios.

In applying eq 2 to cases of multicylinder engines with imperfect distribution, $x$ and $y$ have the significances indicated above, with the addendum "for perfect distribution" to the definition of each. In addition, $X$, with an appropriate subscript, is defined as the ratio of the fuel delivered to a given cylinder to the average fuel delivered per cylinder. The equation for an engine of " $n$ " cylinders, having the distribution represented by $X_{1}, X_{2}, \ldots X_{n}$ is then obtained by replacing the " $x$ " of eq 2 with

$$
x \frac{\sum_{1}^{n} f(X)}{n}
$$

where $f(X)$ is of the same degree in $X$ as the term in eq 2 for which it is being substituted is in $x$. Thus in the first term of eq $2, x$ is replaced by

$$
x \frac{\sum_{1}^{n}\left(\frac{1}{x}\right)}{n}
$$




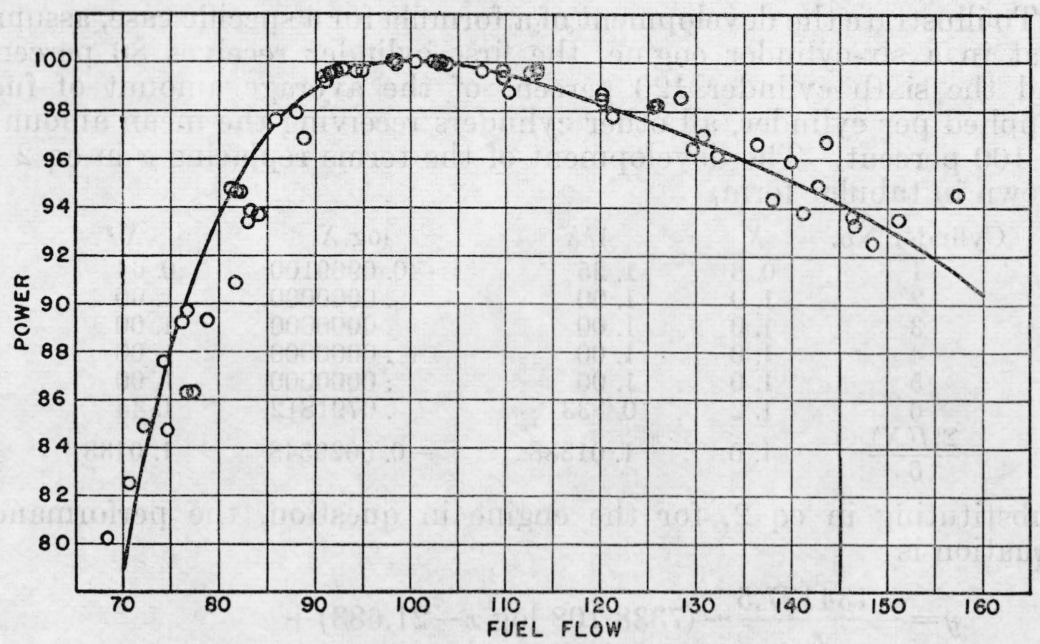

Figure 1.-Single-cylinder-engine test data on which analysis was based.

The curve represents the equation that was fitted to these data. Coordinates were chosen so that a maximum power of 100 was reached at a fuel flow of 100 .

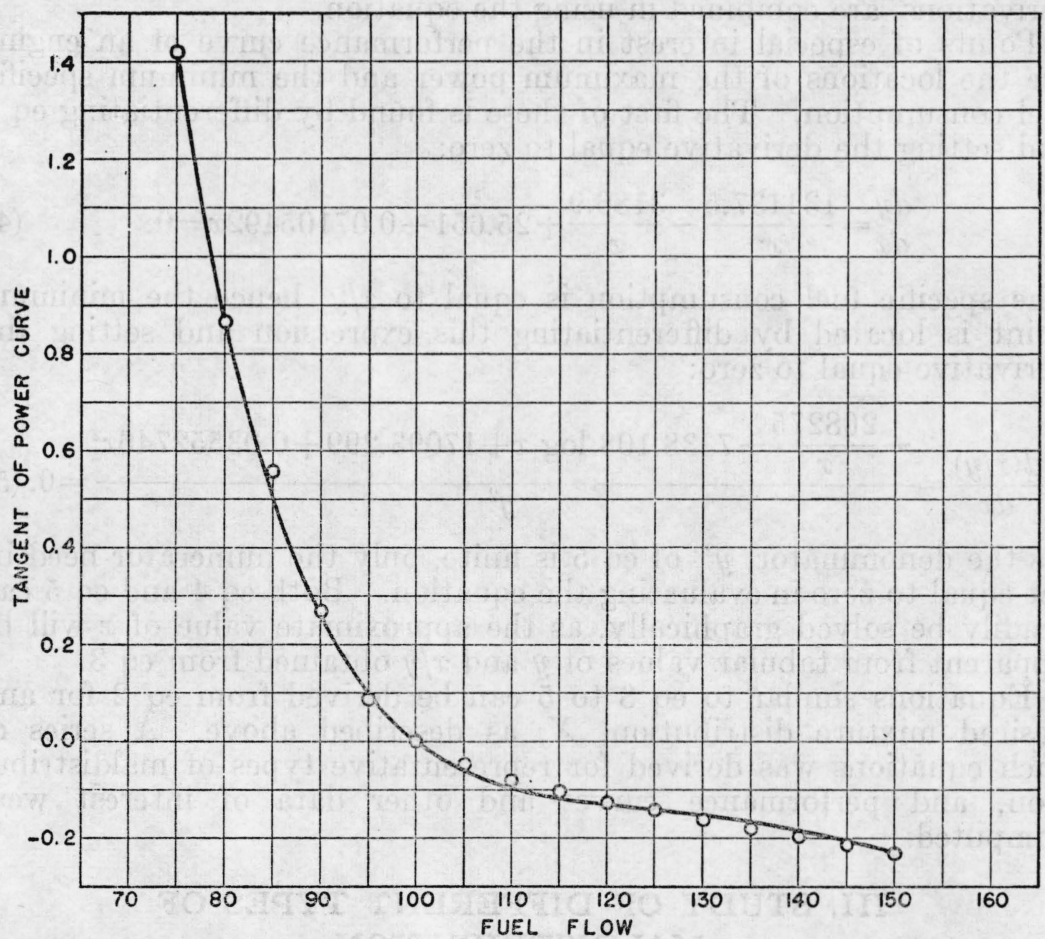

FIGURe 2.-Tangents of power curve shown in figure 1.

The circles show the tangent values derived graphically from the data of figure 1; the curve represents the equation which was fitted to these tangents. 
To illustrate the development of a formula for a specific case, assume that in a six-cylinder engine, the first cylinder receives 80 percent and the sixth cylinder 120 percent of the average amount of fuel supplied per cylinder, all other cylinders receiving the mean amount, or 100 percent. The development of the terms replacing $x$ in eq 2 is shown in tabular form:

$\begin{array}{cllrl}\text { Cylinder No. } & X & 1 / X & \log X & X^{2} \\ 1 & 0.8 & 1.25 & -0.0969100 & 0.64 \\ 2 & 1.0 & 1.00 & .0000000 & 1.00 \\ 3 & 1.0 & 1.00 & .0000000 & 1.00 \\ 4 & 1.0 & 1.00 & .0000000 & 1.00 \\ 5 & 1.0 & 1.00 & .0000000 & 1.00 \\ 6 & 1.2 & 0.833 & .0791812 & 1.44 \\ \frac{\Sigma_{1}^{6} f(X)}{6} & 1.0 & 1.01388 & -0.0029548 & 1.0133\end{array}$

Substituting in eq 2, for the engine in question, the performance equation is

$$
\begin{aligned}
& y=-\frac{134137.5}{x}-(7338.108 \log x-21.683)+ \\
& 13884.716+25.651 x-0.03552746 x^{2}
\end{aligned}
$$

The two constant terms, shown separately in eq 3 to indicate their derivations, are combined in using the equation.

Points of especial interest in the performance curve of an engine are the locations of the maximum power and the minimum specific fuel consumption. The first of these is found by differentiating eq 3 and setting the derivative equal to zero:

$$
\frac{d y}{d x}=\frac{134137.5}{x^{2}}-\frac{3186.9}{x}+25.651-0.07105492 x=0 .
$$

The specific fuel consumption is equal to $x / y$, hence the minimum point is located by differentiating this expression and setting the derivative equal to zero:

$$
\frac{d(x / y)}{d x}=\frac{-\frac{268275}{x}-7338.108 \log x+17093.299+0.03552746 x^{2}}{y^{2}}=0 \text {. }
$$

As the denominator, $y^{2}$, of eq 5 is finite, only the numerator need be set equal to zero in evaluating the equation. Both eq 4 and eq 5 can readily be solved graphically, as the approximate value of $x$ will be apparent from tabular values of $y$ and $x / y$ obtained from eq 3 .

Equations similar to eq 3 to 5 can be derived from eq 2 for any desired mixture distribution, $X$, as described above. A series of such equations was derived for representative types of maldistribution, and performance curves and other data of interest were computed.

\section{STUDY OF DIFFERENT TYPES OF MALDISTRIBUTION}

All computations were based on use of a six-cylinder engine. Computations for an eight-cylinder engine would be more lengthy, with 
little increase in information yielded, whereas those for a four-cylinder engine would not give as many aspects of the problem as desired.

The first series of computations was made for a set of assumed distributions all having the same variance. Specifically, the distributions were so arranged that

$$
\sum_{1}^{6}(1-X)^{2}=0.08
$$

It will be noted that this is the case in the example given in the development of eq 3 . In the seven cases for which computations were made, it was assumed that the total variance arose from: (1) one cylinder rich, (2) one cylinder lean, (3) two cylinders equally rich, (4) one cylinder rich and one equally lean, (5) two cylinders equally lean, (6) two cylinders rich and two equally lean, and, (7) three cylinders rich and three equally lean. The calculated performances under each of these conditions, and also for perfect distribution (case 0 ) are shown in table 1. In subsequent use the above types of distribution are identified by the number in parenthesis to which is appended the variance; the first case thus is 1.08.

Lines 2 and 3 of table 1 list the number of cylinders receiving richer and leaner mixtures than would be the case if perfect distribution prevailed. The number of cylinders not covered in lines 2 and 3 are assumed to receive the same mixture as with perfect distribution. The relative fuel flows to the rich and the lean cylinders are given in lines 4 and 5 , the flow for perfect distribution being taken as unity.

TABLE 1.-Effect of distribution on performance

\begin{tabular}{|c|c|c|c|c|c|c|c|c|}
\hline $\begin{array}{l}\text { 1. Case number (variance of } 0.08 \text { ) } \\
\text { 2. Number of cylinders rich } \\
\text { 3. Number of cylinders lean } \\
\text { 4. Relative fuel to each cylinder, } \\
\text { rich } \\
\text { 5. Relative fuel to each cylinder, } \\
\text { lean }\end{array}$ & $\begin{array}{l}0 \\
0 \\
0\end{array}$ & $\begin{array}{l}1.08 \\
1 \\
5\end{array}$ & $\begin{array}{l}2.08 \\
5 \\
1\end{array}$ & $\begin{array}{l}3.08 \\
2 \\
4\end{array}$ & $\begin{array}{l}4.08 \\
1 \\
1\end{array}$ & $\begin{array}{l}5.08 \\
4 \\
2\end{array}$ & $\begin{array}{l}6.08 \\
2 \\
2\end{array}$ & $\begin{array}{l}7.08 \\
3 \\
3 \\
1.115\end{array}$ \\
\hline $\begin{array}{l}\text { 6. Maximum power } \\
\text { 7. Fuel flow for maximum power } \\
\text { 8. Specific fuel consumption at max- }\end{array}$ & $\begin{array}{l}100.00 \\
100.0\end{array}$ & $\begin{array}{l}99.44 \\
103.1\end{array}$ & $\begin{array}{l}98.13 \\
108.5\end{array}$ & $\begin{array}{c}99.23 \\
104.2\end{array}$ & $\begin{array}{l}98.86 \\
105.4\end{array}$ & $\begin{array}{c}98.76 \\
106.2\end{array}$ & $\begin{array}{c}99.00 \\
105.2\end{array}$ & $\begin{array}{c}99.04 \\
105.1\end{array}$ \\
\hline & 1.000 & 1. 037 & 1. 105 & 1. 050 & 1. 066 & 1.075 & 1.062 & 1. 061 \\
\hline $\begin{array}{l}\text { consumption } \\
\text { 10. Minimum specific fuel consump- } \\
\text { tion in fing range }\end{array}$ & 0.851 & 0.879 & $(0.917)$ & $\begin{array}{r}0.886 \\
.886\end{array}$ & $(0.896)$ & $\begin{array}{r}(0.900) \\
.906\end{array}$ & $\begin{array}{r}(0.893) \\
.895\end{array}$ & $\begin{array}{r}0.892 \\
.892\end{array}$ \\
\hline $\begin{array}{l}\text { 11. Fuel flow at minimum of specific } \\
\text { fuel consumption curve } \\
\text { 12. Firing range, minimum fuel flow- } \\
\text { 13. Firing range, maximum fuel flow } \\
\text { 14. Firing-range ratio }\end{array}$ & $\begin{array}{c}77.0 \\
70.0 \\
160.0 \\
2.29\end{array}$ & $\begin{array}{c}79.0 \\
73.8 \\
127.2 \\
1.72\end{array}$ & $\begin{array}{r}80.7 \\
94.4 \\
152.1 \\
1.61\end{array}$ & $\begin{array}{r}79.3 \\
76.2 \\
137.5 \\
1.80\end{array}$ & $\begin{array}{r}79.7 \\
87.5 \\
133.3 \\
1.52\end{array}$ & $\begin{array}{c}80.0 \\
83.7 \\
147.9 \\
1.77\end{array}$ & $\begin{array}{r}79.6 \\
81.5 \\
140.2 \\
1.72\end{array}$ & $\begin{array}{r}79.6 \\
79.1 \\
143.4 \\
1.81\end{array}$ \\
\hline
\end{tabular}

-Parentheses indicate value lies outside firing range.

Lines 6 and 7 of table 1 give the maximum power developed, and the fuel consumption at which it occurs. Line 8 gives the specific fuel consumption at maximum power. Line 9 gives the minimum of the curve of specific fuel consumption. With some cases of maldistribution, e. g., case 2.08 , this minimum would occur below the fuel flow at which all cylinders will fire. (The firing range is considered, from the single-cylinder-engine test data, to lie between fuel flows of 70 and 160 , for perfect distribution). Line 10 gives the minimum specific fuel 
consumption attained when the leanest cylinder is on the lean boundary of the firing range. Line 11 gives the fuel flow at the minimum of the curve of specific fuel consumption. The boundary fuel flows for regular firing are given in lines 12 and 13 . In line 14 is given the ratio of fuel flow at the rich boundary to that at the lean boundary of the firing range. These boundaries are, of course, determined by the fuel flow to the engine when the leanest cylinder is receiving a relative fuel flow of 70 and when the richest receives 160 .

It is apparent from table 1 that distributions having the same variance can differ greatly in their effect on performance. Thus the power

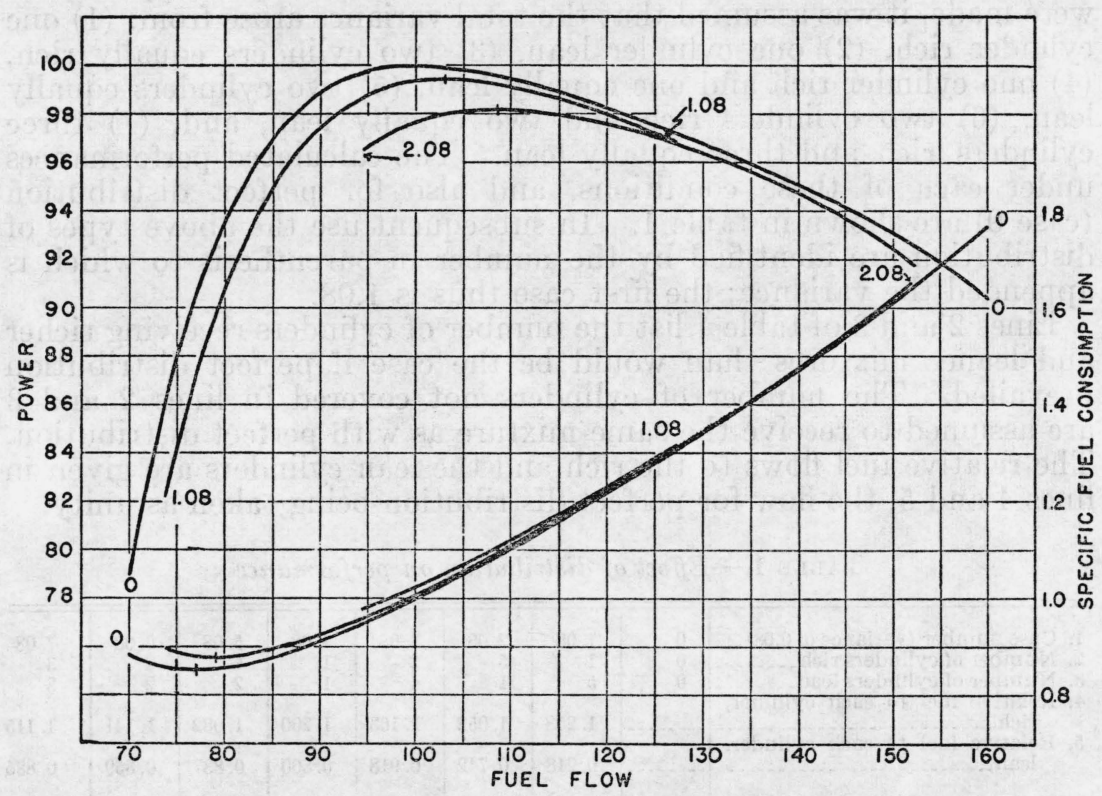

FIGURE 3.-Performance curves for selected distributions.

Case 0 is for perfect distribution, case 1.08 is for one cylinder rich, and case 2.08 is for one cylinder lean. The term .08 on the case number indicates the total variance of the distribution, defined by eq 6 .

loss for "case 2.08 is over three times that for case 1.08 , and the deterioration of minimum specific fuel consumption is over four times as great as for case 1.08. The type of the distribution is of as Imuch importance as the totalivariance. For a given variance, the fworst type is that in which one cylinder is leaner than the remaining cylinders.

The power and the specific fuel consumption curves for cases 0 , 1.08 , and 2.08 are shown in figure 3 . The loss of power is greater, and the increase in minimum fuel consumption is much greater in case 2.08 (one cylinder lean) than in case 1.08 (one cylinder rich), as compared with perfect distribution. The crosses in figure 3 mark the maxima of the power curves and the minima of the specific fuel consumption curves. As shown in figure 3, and also by line 8 of table 1, if the carburetor were set to give maximum power, the specific fuel consumption for case 2.08 would be more than 10 percent greater than with perfect distribution, whereas for case 1.08 , it would be not quite 4 percent greater. 
Cases 3.08 and 5.08 are similar to cases 1.08 and 2.08, respectively, but with much less departure from ideal performance. Case 4.08 (one cylinder rich, one lean) is intermediate between cases 1.08 and 2.08, whereas cases 6.08 and 7.08 are similar to case 4.08 , but with less marked departures from the ideal.

In figure 3, all of the performance curves are plotted against the same fuel flow and power scales, these being chosen so that a maximum power of 100 is obtained with perfect distribution (case 0) at a fuelflow rate of 100 . On this figure, it is easy to recognize an improvement in distribution by the approach of the performance curves to those of the ideal case. In actual practice, however, the power and

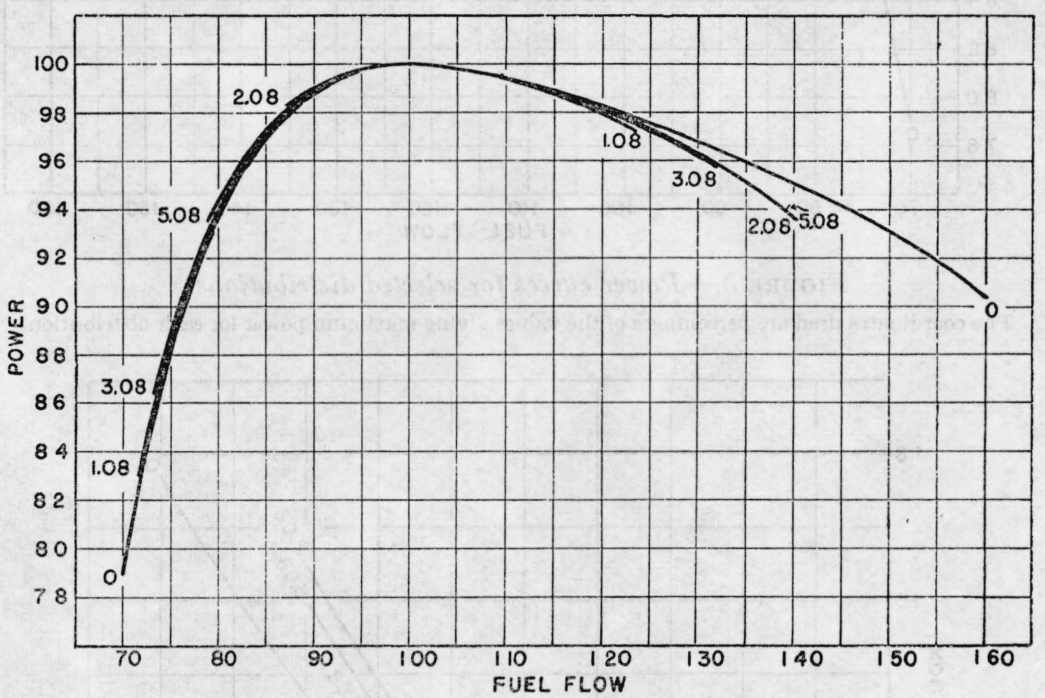

Figure 4.-Power curves for selected distributions.

The coordinates used are percentages of the values giving maximum power for each distribution.

fuel-flow rates for perfect distribution are not ordinarily known. Maximum power, and the rate of fuel flow at which it occurs, vary with atmospheric conditions $[4,5]$, and with other factors. Because of this, it is not determinable with sufficient accuracy to serve as a comparative basis for determining improvement in distribution. Furthermore, if the power curve for each distribution is plotted on scales such that its maximum power is 100 and occurs at a fuel-flow rate of 100 , the curves for the different distributions having equal variance are nearly indistinguishable except for range, as can be seen in figures 4 and 5 . The curves in figure 5 for cases $4.08,6.08$, and 7.08 are also practically identical with the curves for cases $1.08,2.08$ 3.08 , and 5.08 in figure 4. Thus changes in distribution are not accompanied by discernible changes in the shape of the power curve. In actual testing, the information obtained would suffice to plot curves such as figures 4 and 5 , but not figure 3 . 


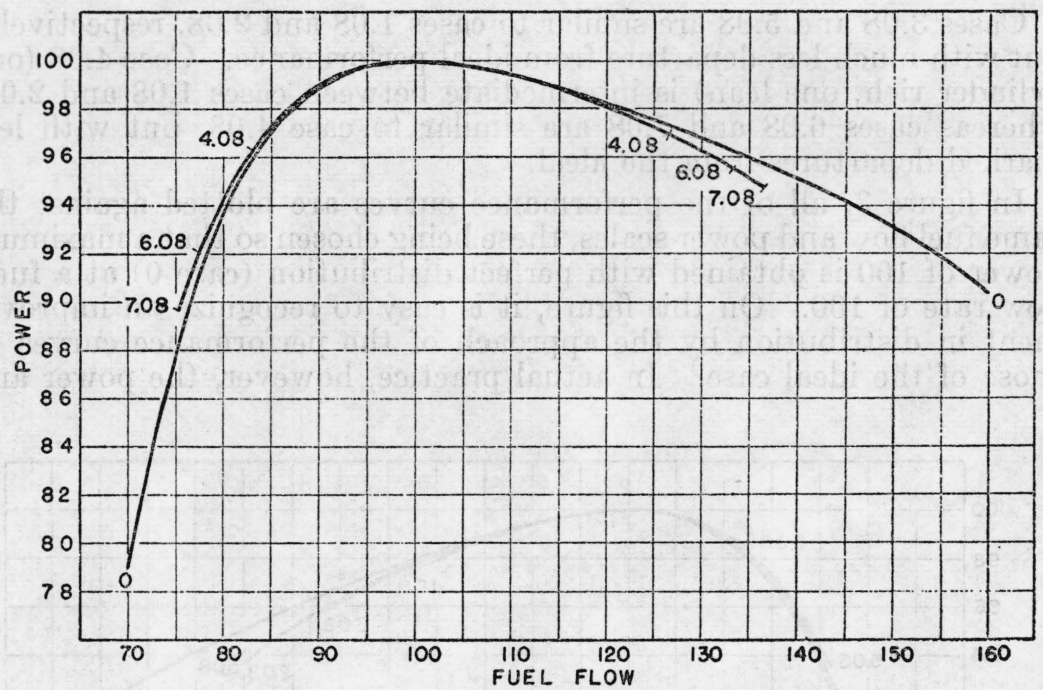

Figure 5.-Power curves for selected distributions.

A. The coordinates used are percentages of the values giving maximum power for each distribution.

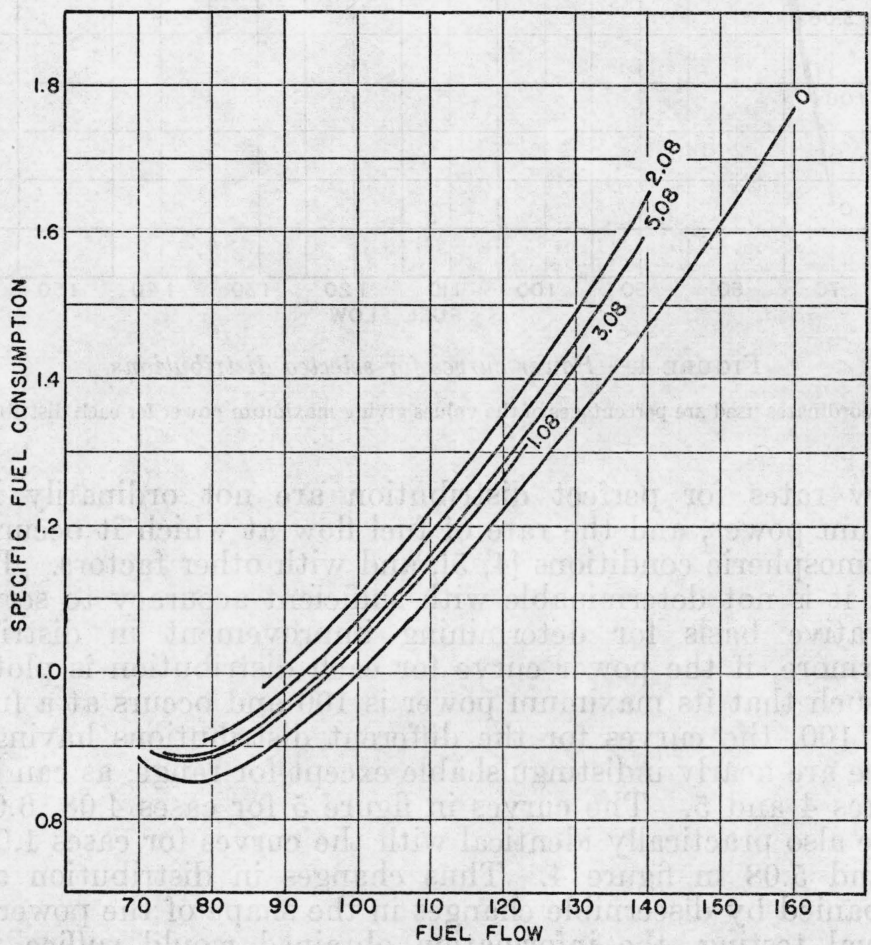

Figure 6.-Specific fuel consumption curves for selected distributions.

The abscissa scale of this figure is the same as that used in figures 4 and 5 . 


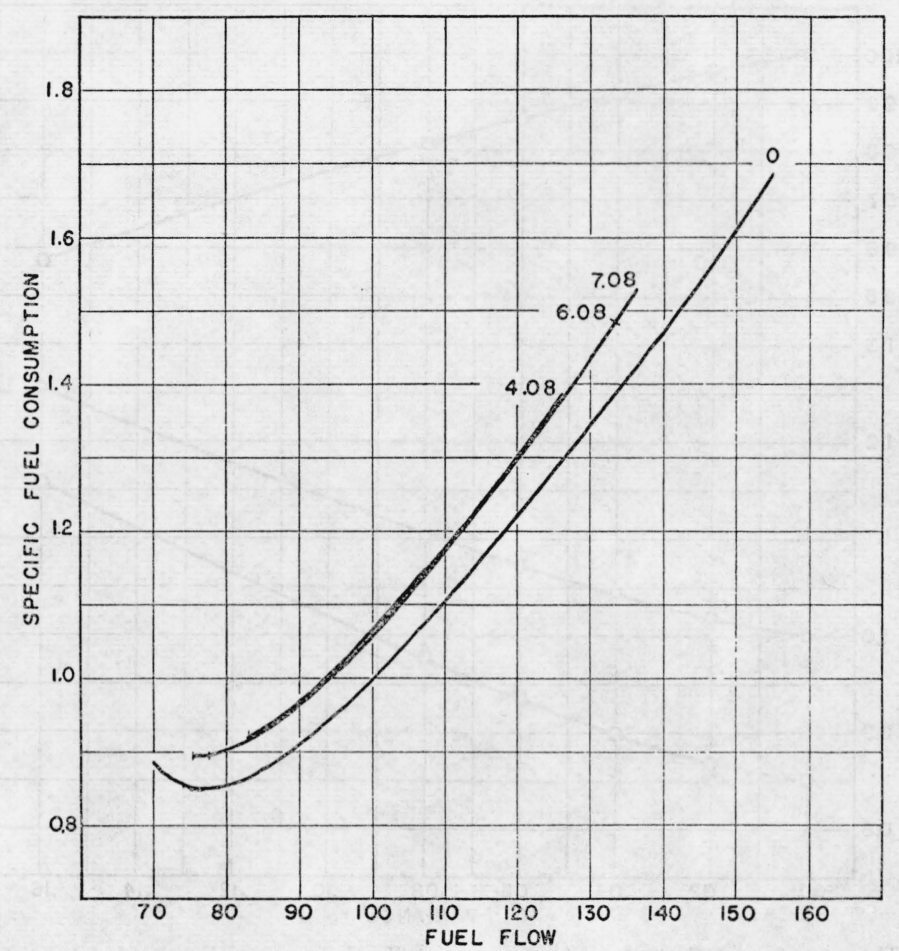

Figure 7.-Specific fuel consumption curves for selected distributions.

The abscissa scale of this figure is the same as that used in figures 4 and 5 .

The specific fuel-consumption curves, plotted in figures 6 and 7 against fuel flow in percent of that giving maximum power, would appear to distinguish readily between good and bad distributions. To determine whether this is generally true, information on other distributions is required.

\section{STUDY OF DIFFERENT DEGREES OF MALDISTRI- BUTION}

For the maldistribution considered thus far, different types having equal variance have been studied. The poorest of these types, case 2 , in which one cylinder was leaner than the rest, was chosen as the subject for a series of computations to determine the effect of variance of the distribution on performance factors. In addition to the variance of 0.08 , used in case 2.08 , values of $0.02,0.04,0.06$, and 0.16 were used. The results of these computations are given in table 2. All performance factors of interest are seen to deteriorate at a somewhat accelerated rate with increase of variance. This is more readily noted from figure 8 , in which maximum power, the specific fuel consumption at maximum power, and the minimum specific fuel consumption are plotted against variance. 


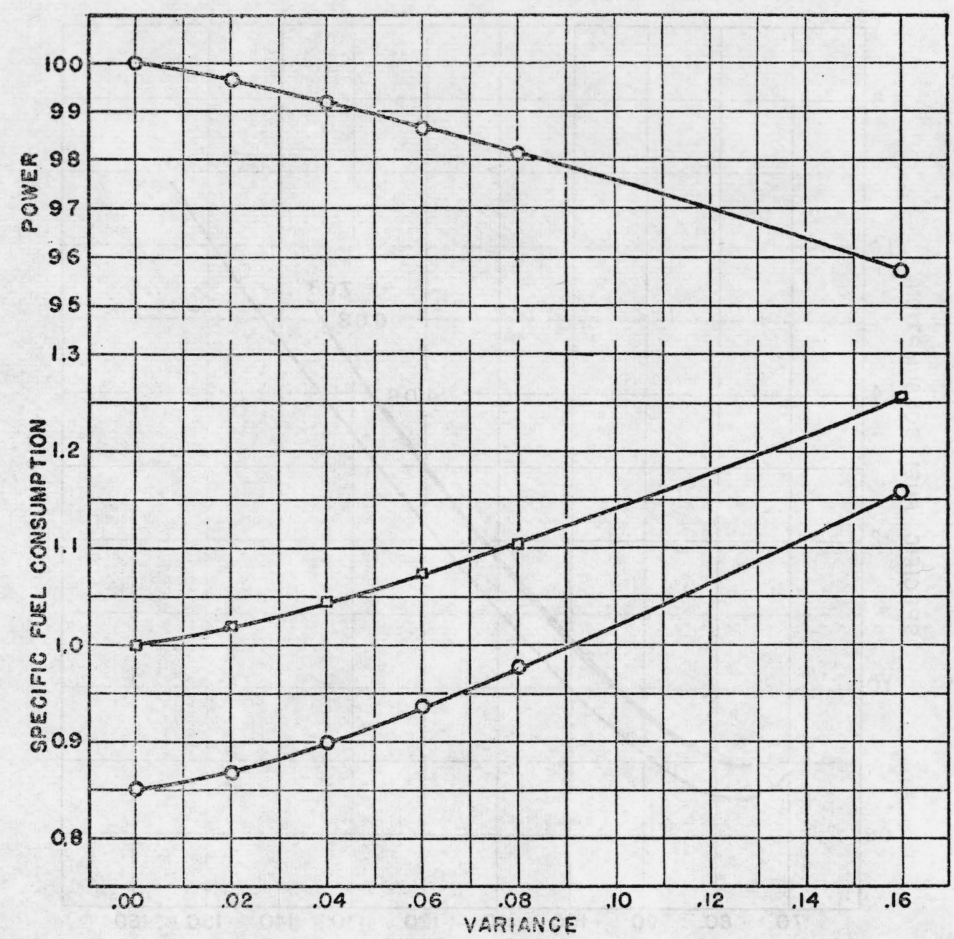

FIGURE 8.-Effect of variance of distribution on engine performance.

Lower curve is minimum specific fuel consumption. Middle curve is specific fuel consumption at maxlmum power. Variance is defined by eq 6.

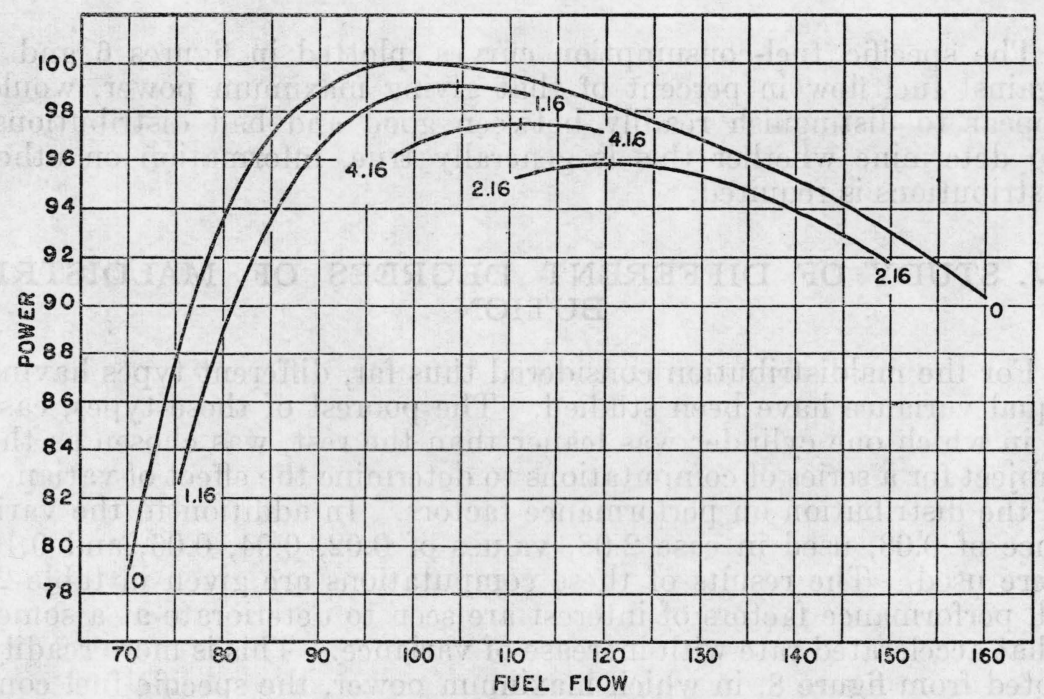

FIGURE 9.-Power curves for three distributions of equal and high variance.

Best performance results when the variance arises from one cylinder being rich (case 1.16); the poorest, when one cylinder is lean (case 2.16). One cylinder rich and one equally lean (case 4.16) gives intermediate performance. 
TABLE 2.-Effect of variance of distribution on performance

[One cylinder lean, remainder rich]

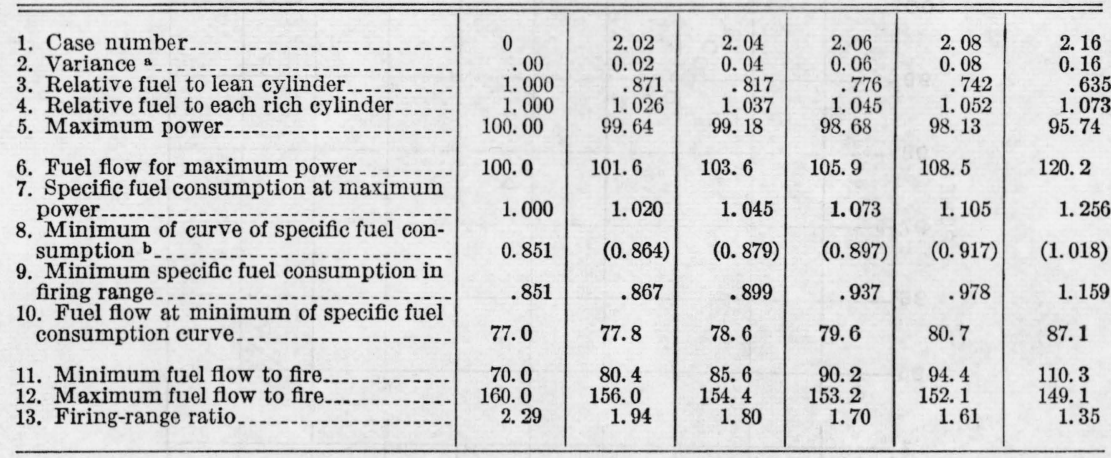

a See eq 6.

barentheses indicate value lies outside firing range.

Computations were made for a total variance of 0.16 for two other types of distribution: case 1 , in which one cylinder is richer than the rest; and case 4, in which one cylinder is leaner and another cylinder is equally richer than the rest. With so high a variance, the power curves, figure 9, are sharply differentiated and show clearly the differences in behavior accompanying these different types of distribution.

In endeavoring to select a criterion for the practical estimation of distribution quality and for the detection of changes therein, a number of factors were investigated. These included ratio of fuel flow at lean misfire to flow for maximum power, ratio of powers at these fuel flows, and product of the ratios of power at lean and at rich misfire to maximum power. Maximum power, specific fuel consumption at maximum power, and minimum specific fuel consumption for the various distributions were plotted against each of these factors. None of these, however, gave as good a correlation as was obtained by plotting the first two of the variables against minimum specific fuel consumption, figure 10. The latter value, directly determinable by test, is either the minimum of the specific fuel consumption curve, if this is reached, or the value reached at lean misfire, if the minimum has not then been attained.

It can be seen from figure 10 that maximum power and its attendant specific fuel consumption are well correlated with the value of minimum specific fuel consumption. This readily observable variable thus is shown to be a satisfactory index of distribution quality. Furthermore, a 1-percent change in maximum power is evidenced by a 5-percent change in minimum specific fuel consumption, showing that the latter is a good criterion for the former. 


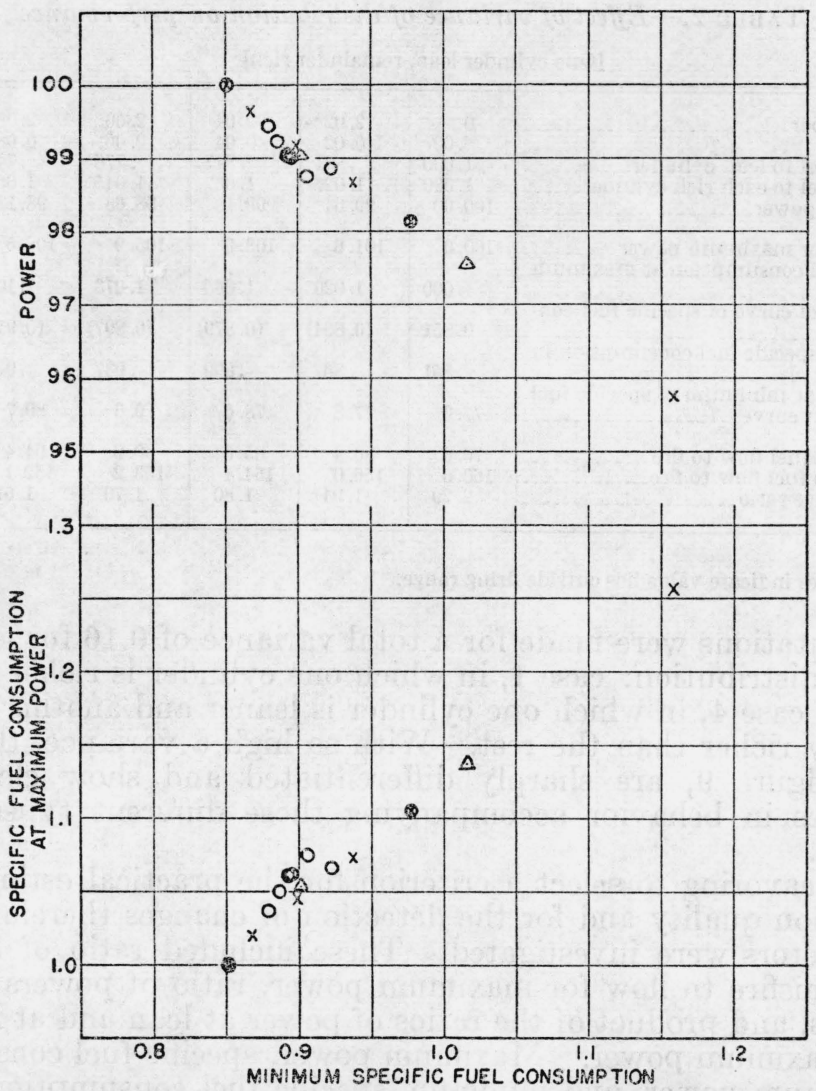

FIGURE 10.-Correlation of maximum power and specific fuel consumption at maximum power with minimum specific fuel consumption.

Minimum specific fuel consumption is seen to be a good criterion of distribution. Circles indicate cases 1 to 7 with a variance of 0.08 ; triangles, cases 1.16 and 4.16; crosses, case 2 with variance of 0.00 to 0.16 .

\section{ESTIMATION OF IMPROVEMENT ATTAINABLE}

It has been shown in the foregoing sections that a change in distribution that improves engine performance in general is accompanied by an improvement in minimum specific fuel consumption. In weighing the advisability of further effort toward manifold improvement, it is desirable to know how much additional improvement is attainable in a given case. This can be determined by the methods given earlier, provided the actual distribution is measured by any appropriate means.

In the research on substitute fuels, a six-cylinder engine was operated on 190-proof alcohol, under normal operating conditions. The mixture distribution was determined by the use of thermocouple spark plugs, as described by Rabezzana and Kalmar [6]. The relative amount of fuel reaching each cylinder is shown by the value of $X$ in the subsequent tabulation. 
To determine the improvement in performance that might be expected with optimum manifolding, values of

$$
\frac{\Sigma_{1}^{6} f(X)}{6}
$$

are first determined as follows:

$\begin{array}{ccccc}\begin{array}{c}\text { Cylin- } \\ \text { der No. }\end{array} & X & 1 / X & \log X & X^{2} \\ 1 & 0.764 & 1.3089 & -0.11691 & 0.5837 \\ 2 & 1.094 & 0.9141 & +.03902 & 1.1968 \\ 3 & 1.069 & .9355 & +.02898 & 1.1428 \\ 4 & 1.046 & .9560 & +.01953 & 1.0941 \\ 5 & 1.214 & .8237 & +.08422 & 1.4738 \\ 6 & 0.813 & 1.2300 & -.08991 & 0.6610 \\ & & & & \\ \sum_{1}^{6} f(X) & & & & \\ 6 & 1.000 & 1.0280 & -.005845 & 1.0254\end{array}$

The performance equation is then formed, as in the example given earlier by the substitution of

for $x$ in eq 2 :

$$
x \frac{\sum_{1}^{6} f(X)}{6}
$$

$$
\begin{aligned}
& y=-\frac{136004.4}{x}-(7338.108 \log x-42.891)+ \\
& 13884.716+25.651 x-0.035950 x^{2}
\end{aligned}
$$

The derivatives of the performance equation and of the specific fuel consumption equation are also formed:

$$
\begin{gathered}
d y / d x=\frac{136004.4}{x^{2}}-\frac{3186.9}{x}+25.651-0.071900 x \\
\frac{d(x / y)}{d x}=\frac{\frac{-272008.8}{x}-7338.108 \log x+17114.51+0.035950 x^{2}}{y^{2}}
\end{gathered}
$$

The fuel consumption at which maximum power occurs is obtained by evaluating eq 8 at a series of values of $x$ in the probable range:

$\begin{array}{cc}x & d y / d x \\ 109 & +0.023 \\ 110 & +.010 \\ 111 & -.002\end{array}$

From this tabulation, it is seen that the maximum power $(d y / d x=0)$ occurs at $x=110.8$.

The leanest cylinder, no. 1 , has a relative fuel flow of 0.764 . It will misfire when the actual fuel flow to it reaches 70 , or at an engine fuel flow of 70/.764 or 91.6. At this value of $x$, the numerator of eq 9 equals +49.99 , indicating that the specific fuel consumption is increasing with fuel flow at this point. The minimum specific fuel 
consumption therefore occurs at $x=91.6$, the point of lean misfire. Had eq 9 yielded a negative value, the point of minimum specific fuel consumption would be at a higher value of $x$, and would be found by the substitution of successive values of $x$, as was done above in the case of eq 8. The (interpolated) value of $x$ causing eq 9 to equal zero would then be the fuel flow for minimum specific fuel consumption.

The values of $x$ at which minimum specific fuel consumption and maximum power are attained, are next substituted in eq 7, to obtain the power at these values. From these results, the specific fuel consumptions at these points are computed. These values, in comparison with those for perfect distribution (case 0), were:

\begin{tabular}{|c|c|c|c|c|}
\hline & \multicolumn{2}{|c|}{$\begin{array}{l}\text { Minimum specific fuel con- } \\
\text { sumption }\end{array}$} & \multicolumn{2}{|c|}{ Maximum power } \\
\hline & Example & Case 0 & Example & Case 0 \\
\hline $\begin{array}{l}x \text { (fuel flow) } \\
y \text { (power) } \\
x / y \text { (specific fuel consumption) }\end{array}$ & $\begin{array}{l}91.6 \\
94.2 \\
0.972\end{array}$ & $\begin{array}{l}77.0 \\
90.5 \\
0.851\end{array}$ & $\begin{aligned} 110.8 \\
97.8 \\
1.132\end{aligned}$ & $\begin{array}{l}\text { 100. } 0 \\
100.0 \\
1.000\end{array}$ \\
\hline
\end{tabular}

In the example in question, therefore, optimum manifolding would result in 2-percent gain in maximum power, and in over 10-percent gain in fuel economy.

\section{FACTORS NOT CONSIDERED IN ANALYSIS}

It will be noted that the matter of spark advance has not been mentioned thus far. In the single-cylinder-engine tests on which this analysis is based the spark advance was optimum at each mixture ratio employed. This condition cannot be duplicated in a multicylinder engine, except in the case of perfect distribution. The different fuel-air mixtures reaching the several cylinders would require different spark advances for optimum performance. A study of this matter indicates, however, that the departure from the curves given herein will be inappreciable, except at very lean or very rich mixtures. If a fixed spark advance is used in multicylinder operation, as is customary, the power curves will be shortened and will be lower at lean and at rich mixtures than those shown herein.

It has also been tacitly assumed in this analysis that the variance of a distribution is the same at all mixture ratios. Actually, this is not the case. Vaporized fuel is distributed fairly evenly to all cylinders. The variance of a distribution arises almost entirely from maldistribution of liquid fuel. At richer mixture ratios, an increasing: percentage of the fuel remains unvaporized. Hence the variance of distribution, for a given engine and fuel, tends to increase at richer mixture ratios. If the variance of distribution as discussed herein be assumed to apply at the lean end of the power curve, the effect of this factor can be roughly approximated by rotating the power curve clockwise about the lean end. Neither this effect nor that of departure of spark advance from optimum for the individual cylinders will invalidate the correlation shown in figure 10 . 


\section{CONCLUSIONS}

The effects on engine performance of typical cases of maldistribution of the fuel-air mixture have been evaluated analytically from singlecylinder-engine test data. It has been shown that minimum specific fuel consumption is a good index of distribution, improvement in this variable generally being accompanied by improvement in the other engine-performance variables of interest. A method has been developed for ascertaining the attainable improvement over a given distribution.

\section{REFERENCES}

[1] Donald B. Brooks, J. Research NBS 35, 1 (1945) RP1660.

[2] Jesse T. Duck and C. S. Bruce, J. Research NBS 35, 439 (1945) RP1681.

[3] Stanwood W. Sparrow, NACA Technical Note 162 (1923).

[4] Donald B. Brooks, BS'J. Research 3, 795 (1929) RP118.

[5] D. B. Brooks, and E. A. Garlock, NACA Report 426 (1932).

[6] Hector Rabezzana and Stephen Kalmar, Automotive Ind. 66, 450 and 486 (March 19 and 26, 1932).

Washington, January 5, 1946. 